\title{
O Conselho de Desenvolvimento Econômico e Social e a nova agenda desenvolvimentista no Brasil $^{1}$
}

Priscilla Ribeiro dos Santos

Universidade Federal do Rio Grande do Sul (UFRGS)

\section{O Conselho de Desenvolvimento Econômico e Social e a nova agenda desenvolvimentista no Brasil}

No Brasil, inaugura-se um período de recuperação das capacidades de investimento do Estado e de ampliação de espaços institucionais para a participação social com a eleição do Presidente Lula em 2003. O Conselho de Desenvolvimento Econômico e Social (CDES) foi criado com o objetivo de debater as políticas desenvolvimentistas em diálogo com a sociedade civil. Por meio da análise documental, este artigo visa analisar em que medida o CDES contribuiu para a retomada da agenda desenvolvimentista nos últimos anos.

Palavras-chave: sociedade civil, democracia, desenvolvimento socioeconômico, plano de desenvolvimento, políticas públicas

\footnotetext{
${ }^{1}$ Uma primeira versão deste artigo foi apresentada no VII Congresso Latino-americano de Ciência Política (ALACIP), em 2013, na área de trabalho Participação, Representação e Atores Sociais. Agradeço as contribuições dos pareceristas anônimos da Revista do Serviço Público, que proporcionaram o enriquecimento deste trabalho.
}

Artigo recebido em dezembro de 2013. Versão final em maio de 2014. 


\section{El Consejo de Desarrollo Económico y Social/Brasil y la nueva agenda desarrolista en Brasil}

En Brasil, se inauguró un período caracterizado por la capacidad de recuperación de la inversión del Estado y por la ampliación del diálogo con la sociedad civil desde la elección del Presidente Lula en el 2003. El Consejo de Desarrollo Económico y Social (CDES) se estableció con el objetivo de discutir las políticas de desarrollo en el diálogo con la sociedad civil. A partir de el análisis de documentos, este artículo tiene por objetivo analizar como la creación del CDES contribuyó a la agenda del desarrollo en los últimos años.

Palabras-clave: sociedad civil, democracia, desarrollo económico y social, plano de desarrollo, política pública

\section{The Brazilian Council for Economic and Social Development and the new developmentalist agenda in Brazil}

In Brazil, a period characterized by the recovery of state investment capacity and the expansion of dialogue with civil society has begun since the election of President Lula in 2003. The Council for Economic and Social Development (CDES) was created with the objective of discussing development policies in dialogue with civil society. Based on documental analysis, this article seeks to understand how the CDES has contributed to the Brazilian development agenda in recent years.

Keywords: civil society, democracy, social and economic development, development plan, public policy 


\section{Introdução}

Na América Latina, a retomada da agenda desenvolvimentista, nos últimos anos, buscou construir alternativas às políticas neoliberais, gestadas nas décadas de 1980 e 1990. Com base no diagnóstico do fracasso das políticas de Estado mínimo, governos de esquerda e centro-esquerda da região propõem um novo projeto político, baseado na retomada das capacidades estatais e no enfrentamento das desigualdades socioeconômicas. No Brasil, esse processo teve como característica a ampliação dos fóruns participativos para o debate das políticas públicas a partir da eleição do Presidente Lula em 2003. Nesse sentido, foi criado o Conselho de Desenvolvimento Econômico e Social (CDES) com o objetivo de assessorar a Presidência da República por meio da concertação entre trabalhadores, empresários e segmentos da sociedade civil sobre a temática do desenvolvimento.

Este estudo tem como objetivo geral analisar em que medida a criação de um fórum participativo com composição majoritária da sociedade civil contribuiu para a retomada da agenda desenvolvimentista no Brasil. Para tanto, a pesquisa empreendida tem caráter qualitativo, com base na análise documental referente à produção do CDES no período de 2003 a 2010. Tendo em vista o recente processo de ampliação dos espaços institucionais para diálogo com a sociedade civil na administração federal, este artigo visa contribuir para os estudos sobre a temática do desenvolvimento, destacando o potencial de fóruns participativos para a democratização dos processos decisórios e qualificação da gestão pública.

Dividido em três seções, primeiramente, o artigo propõe uma breve reflexão a respeito das características do projeto desenvolvimentista em um contexto democrático. Se, desde a década de 1980, o debate sobre o desenvolvimento esteve encoberto pela preocupação com a estabilidade econômica e com o controle da inflação, a partir do governo Lula, ocorre a retomada da agenda desenvolvimentista, tendo como um de seus eixos as ações para o enfrentamento da miséria e das desigualdades sociais.

A segunda seção aborda como a participação social foi introduzida na estrutura do Governo Federal como um instrumento de democratização da gestão pública. Tendo-se firmado o compromisso de ampliação do diálogo com a sociedade civil, a partir de 2003, foram desenvolvidas ações no sentido de incorporar a participação social tanto no planejamento governamental, quanto na gestão de determinadas políticas por meio da atuação de conselhos e conferências em diversas áreas.

Composto majoritariamente por representantes da sociedade civil, o CDES se inseriu no debate sobre as políticas desenvolvimentistas, tendo elaborado três documentos estratégicos numa perspectiva de planejamento estatal de médio e 
longo prazos: a Agenda Nacional para o Desenvolvimento (AND), os Enunciados Estratégicos para o Desenvolvimento (EED) e a Agenda Nacional para um Novo Ciclo de Desenvolvimento (ANC). Tendo em vista que o debate sobre políticas promotoras de desenvolvimento envolve um campo de lutas e disputas entre Estado e organizações da sociedade civil, a terceira seção busca analisar se a criação do CDES possibilitou a ampliação da base de apoio do governo às políticas centradas numa concepção de Estado neodesenvolvimentista.

\section{A retomada da agenda desenvolvimentista no Brasil}

Tendo em vista que, ao longo do século $X X$, nas mais diversas sociedades, o desenvolvimentismo se caracterizou como um processo assimétrico, heterogêneo e desigual, tornam-se necessárias novas convenções sobre o desenvolvimento a fim de contemplar, num projeto democrático, a equidade e a justiça social. Nesse sentido, são diversos os desafios para a construção de Estados desenvolvimentistas na atualidade. Segundo Diniz (2013, p. 10),

A construção de um estado desenvolvimentista deriva de um processo de experimentação e aprendizado constantes, que pode beneficiar-se de análises comparativas, mas não pode deixar de levar em conta a trajetória de cada país e suas condições institucionais peculiares. Em segundo lugar, desenvolvimento e estado desenvolvimentista estão estreitamente interligados no processo de produção de novas rotas desenvolvimentistas. Eis porque não podem ser analiticamente separados. Em terceiro lugar, somente uma abordagem multidisciplinar capaz de conjugar os aportes da moderna teoria do desenvolvimento com as análises do papel das instituições e da política pode responder aos desafios de interpretar essa nova construção.

Embora não haja consenso sobre um modelo universal de Estado desenvolvimentista, Evans (2010) postula o papel determinante das instituições estatais para o sucesso do desenvolvimento. Com base na experiência histórica e na teoria do desenvolvimento, o autor argumenta que sem um Estado desenvolvimentista não há desenvolvimento. Por isso, as capacidades estatais e as relações entre Estado e sociedade são condições necessárias para a análise dos Estados desenvolvimentistas do século XXI (Evans, 2010).

Entretanto, segundo a leitura de Pires e Gomide (2014), há autores que afirmam que instituições democráticas trariam obstáculos à realização de políticas desenvolvimentistas, tendo em vista que a democracia possui mecanismos que dificultam a promoção de consensos entre as elites políticas, sobretudo quanto a transformações rápidas (JoHnson, 1982; LeFTWICH, 1998; WADE, 1990 apud PIRES; Gomide, 
2014, p. 10). Ainda, segundo essa perspectiva, o aumento do número de atores que passaria a exercer influência sobre o sistema político provocaria um excesso de demandas que dificultaria a formação de consensos e a viabilização das políticas em ritmo mais acelerado. Com base na experiência do Estado desenvolvimentista do Leste Asiático, tais autores atribuem centralidade às burocracias estatais e sua capacidade de articulação com as elites econômicas.

Herrlein Jr. (2014) contrasta o Estado desenvolvimentista do Leste Asiático com o modelo proposto de Estado democrático para o desenvolvimento. Segundo o autor, o primeiro modelo foi implementado no pós-Segunda Guerra em países como Taiwan, Coréia do Sul e Japão. Além de promover o dinamismo econômico, esse modelo visava garantir a soberania nacional e a base material para a manutenção das capacidades de defesa, especialmente nos casos de Taiwan e Coréia do Sul.

O modelo do Leste Asiático se caracterizou pela ascensão ao poder de uma elite desenvolvimentista modernizante, que passou a atuar de forma autoritária por meio da subordinação ou marginalização de grupos políticos e organizações. Aliada à exclusão política de setores populares e restrições às liberdades civis, o referido modelo visou à promoção do crescimento econômico e à competitividade internacional, sendo que a promoção de melhores condições de vida para a população foi menos resultado da orientação do Estado do que consequência de um processo de industrialização sustentado (HERRLEIN JR, 2014).

Enquanto um conceito teórico-normativo e não descritivo, Herrlein Jr. (2014) propõe um modelo de Estado desenvolvimentista orientado por princípios democráticos, no qual o padrão de relações entre Estado e sociedade difere das experiências desenvolvimentistas até então existentes. Tendo em vista que a democracia permite processar os conflitos sociais de forma pacífica por vias institucionais, tem-se um ambiente propício para discutir os sentidos do desenvolvimento e os fins almejados. Segundo o autor, esse modelo busca tornar o desenvolvimento um processo endógeno, democrático, criativo, atento às demandas sociais e garantidor da expansão das capacidades humanas².

Segundo Cepêda (2012), o modelo nacional-desenvolvimentista no Brasil, tanto em suas feições democráticas quanto autoritárias, partiu do diagnóstico da condição de subdesenvolvimento e atribuiu centralidade à superação dos estrangulamentos do mundo da produção mediante processo de industrialização.

\footnotetext{
2 Para a construção do modelo, o autor utiliza o conceito de desenvolvimento endógeno de Celso Furtado (1984) e as contribuições de Amartya Sen (2000) sobre as capacidades humanas.
} 
Em suma, tinha como base a industrialização substitutiva de importações, o intervencionismo estatal e o nacionalismo. Concebia a distribuição e a elevação da qualidade de vida enquanto subprodutos do crescimento econômico.

Com a redemocratização, a luta contra a inflação substitui o desenvolvimento como principal questão política na década de 1990. Nos governos Collor (1990-1992), Itamar Franco (1992-1994) e Fernando Henrique Cardoso (1995-2002), há uma clara ruptura com o velho padrão nacional-desenvolvimentista pela adoção de uma orientação moderadamente liberal e internacionalizante. Como produto das orientações neoliberais, as privatizações resultaram na perda do controle do Estado sobre setores estratégicos como telecomunicações, estradas e energia. Também a política macroeconômica inaugurada pelo Plano Real acentuou a tendência à integração da economia brasileira à economia mundial, gerando mais fragilidades e dependência em relação às oscilações do mercado e às especulações financeiras.

A continuidade das políticas neoliberais versus a implementação de um novo projeto de desenvolvimento deram os contornos da campanha presidencial de 2002. Embora houvesse o reconhecimento da necessidade de um novo modelo de desenvolvimento, que alavancasse o crescimento econômico, havia certo receio quanto a mudanças drásticas no sistema financeiro e o retorno de um contexto de hiperinflação. Na tentativa de responder aos ataques a sua candidatura, Lula escreve a Carta ao Povo Brasileiro. O documento diagnostica os fracassos das políticas neoliberais e propõe um novo contrato social, capaz de assegurar o crescimento com estabilidade (SILVA, 2002. p 2). Além de firmar o compromisso de uma "transição lúcida e criteriosa", que correspondesse aos anseios da população, o documento também defendeu o cumprimento dos contratos assumidos anteriormente quanto à dívida pública doméstica e externa e ao programa de auxílio emergencial do Fundo Monetário Internacional (FMI) ${ }^{3}$.

\footnotetext{
${ }^{3}$ Em análise sobre a relação entre o Governo FHC e o empresariado, Diniz (2006) afirma que, a partir de 1998, houve um movimento por parte de grandes entidades como a Federação das Indústrias do Estado de São Paulo (Fiesp) no sentido de contestar a política econômica em favor da retomada do crescimento. $O$ descontentamento com o Governo FHC deu os contornos da campanha de 2002, sendo que parte da elite empresarial expressou apoio à candidatura de Lula. Segundo Diniz, a estratégia de moderação teve como passo fundamental a aliança com o Partido Liberal $(\mathrm{PL})$, que garantiu ao empresário José Alencar o cargo de vice-presidente (DINIZ, 2006).
} 
Em alternativa às políticas privatizantes e de defesa de um Estado mínimo, vigentes no período anterior, foram construídas as bases para um processo de dinamismo econômico, atrelado ao compromisso político de enfrentamento das desigualdades sociais. Embora na década de 1990 os impulsos para a liberalização da economia tenham retardado a viabilização de políticas sociais, tem-se um novo cenário a partir de 2003.

Quando no poder, o Governo Lula atenuou o radicalismo antineoliberal, que vinha caracterizando o discurso do Partido dos Trabalhadores durante a década de 1990. Mesmo diante das críticas de setores de esquerda, o governo manteve as políticas macroeconômicas fundadas num tripé neoliberal, composto por uma política monetária determinada pelas metas de inflação, câmbio flutuante e uma política fiscal que visou manter um superávit primário, compensando o déficit nominal das contas públicas (MoraIS; SAAD-FILHO, 2011, p. 508). Ainda, segundo Morais e Saad-Filho (2011, p. 511), há divergências quanto aos motivos que levaram à continuidade das políticas neoliberais nos primeiros anos do governo: enquanto alguns defendem essa continuidade como um produto da fraqueza ideológica do governo (PAULANI, 2003), outros afirmam que a continuidade estaria relacionada a uma correlação de forças políticas, que impunha o abandono do radicalismo antineoliberal para a gestão do Estado (BARBOSA; SOUZA, 2010; MoRAIS; SAAD-FILHO, 2005).

De modo geral, segundo Erber (2011), o Brasil tem convivido com duas convenções sobre o desenvolvimento: a defendida por economistas liberais, que reagem ao aumento da participação do Estado na economia e ao protagonismo das empresas e bancos públicos; e a orientação pós-keynesiana, que reúne economistas em torno da expressão "novo desenvolvimentismo"". Em contraste com a primeira orientação, que postula a centralidade do mercado enquanto instituição responsável pela alocação eficaz dos recursos, a orientação do novo desenvolvimentismo parte de uma inspiração keynesiana e se fundamenta no ativismo estatal e na sua capacidade de regular os mercados e promover políticas industriais estratégicas.

\footnotetext{
${ }^{4}$ Sobre o debate entre as convenções institucionalista, de inspiração neoclássica e referenciada na Nova Economia Institucional, e desenvolvimentista, de inspiração keynesiana, sugere-se Erber (2011), BresserPereira, Theuer (2012).
} 
Segundo a orientação novo ou neodesenvolvimentista ${ }^{5}$, a atuação do governo ocorre prioritariamente em áreas de infraestrutura, programas habitacionais, investimento em inovação, aumento do consumo, redução do desemprego e política externa independente (Bresser-Pereira; Theuer, 2012). Diferentemente do nacional-desenvolvimentismo das décadas de 1950 a 1970, atualmente, o Estado desenvolvimentista brasileiro compete com outros países no quadro da globalização, aproveita melhor o mercado interno capitalista, é democrático e pretende ser socialmente inclusivo (Bresser-Pereira; Theuer, 2012, p. 812). Tem como premissas: a coexistência de Estado e mercado fortes; a viabilização de políticas macroeconômicas adequadas para o crescimento econômico sustentado; e a compatibilização de crescimento e equidade social (Sıcsú et al., 2005).

Ao longo do Governo Lula, essas duas concepções, a liberal e a desenvolvimentista, disputaram a hegemonia. Apesar de terem pressupostos ontológicos e analíticos distintos, a convivência entre elas foi possível, por um lado, pela força da coalizão conservadora, somada à percepção de que as políticas desenvolvimentistas e de combate à pobreza não afetariam os próprios interesses dessa coalizão, e, por outro lado, pelo entendimento de que taxas de crescimento restritas não criariam obstáculos para a inclusão social (ERBER, 2011). Nesse sentido, a aparente contradição entre as duas orientações assume a figura de um reformismo fraco, nos termos propostos por Singer (2012), tendo em vista que “(...) para a burguesia, o reformismo fraco representa um caminho possível, embora não o de sua predileção, para o desenvolvimento do capitalismo no País, sem que sua posição esteja ameaçada" (SINGER, 2012, p. 207).

$\mathrm{O}$ autor ainda afirma que a emergência do lulismo, enquanto um realinhamento eleitoral que possibilitou margem de manobra para o segundo mandato, somente foi possível graças à associação entre uma conjuntura econômica internacional favorável e a adoção de políticas focalizadas de combate à extrema pobreza e de ativação do mercado interno ${ }^{6}$. Nesse sentido, Lula teria escolhido um caminho

\footnotetext{
${ }^{5}$ A utilização dos prefixos "neo" ou "novo" denotam uma orientação que se diferencia do modelo nacionaldesenvolvimentista vigente na América Latina a partir da década de 1930 até o choque do petróleo, em 1970, e a eclosão da crise da dívida externa no início dos anos 1980. Para uma compreensão ampliada das diferenças entre o novo e o nacional-desenvolvimentismo, ver Gonçalves (2012) e Cepêda (2012).

${ }^{6}$ Dentre as políticas implementadas pelo Governo Lula, destacam-se a política de valorização do salário mínimo, o programa habitacional Minha Casa, Minha Vida e as políticas de proteção social, em especial, o programa de transferência de renda, Bolsa Família (PBF). Tais políticas garantiram a dinamização da economia, sendo que os benefícios do sistema de proteção social e a valorização do salário mínimo deram condições para a ampliação do mercado interno.
} 
intermediário ao neoliberalismo da década anterior, aproveitando-se do ciclo de expansão capitalista e do boom das commodities entre 2003 e 2008 (SINGER, 2012, p.21).

Frente ao escândalo político e midiático do mensalão e à busca por ampliação das alianças a partir do segundo mandato, a equipe de governo sofre alterações, com destaque para a substituição do Ministro da Fazenda. Nesse momento, acentua-se a orientação desenvolvimentista, tendo como textos-chave o Programa de Aceleração do Crescimento (PAC 2007-2010) e a Política de Desenvolvimento Produtivo (ERber, 2011; Morals, SAAd-FILHo, 2011). Se, até 2005 o Governo Lula adotou uma política macroeconômica com foco no controle da inflação e na redução do endividamento do setor público, a partir de 2006 passou a promover ações no sentido de acelerar o crescimento, aumentando os investimentos e estimulando a geração de emprego (BARBOSA, 2013).

O PAC, criado em 2007, foi um dos principais pilares para a sustentação prolongada do crescimento econômico brasileiro. Segundo Oliveira (2013), em termos de planejamento governamental, o programa chegou a assumir parte substantiva das atribuições do Plano Plurianual 2008-2011, principalmente na área de infraestrutura. A primeira versão do PAC, vigente até 2010, estimulou investimentos em infraestrutura nas áreas de saneamento, habitação, transporte, energia e recursos hídricos ${ }^{7}$. Sobre a criação do PAC, Barbosa $(2013$, p. 78) ressalta:

A estratégia do Governo Federal, pela primeira vez em muitas décadas, foi apoiar a formação de capital por parte do setor privado e, simultaneamente, aumentar o investimento público em infraestrutura. Além do aumento do investimento propriamente dito, o PAC também incluiu uma série de desonerações tributárias para incentivar o investimento privado e o desenvolvimento do mercado de consumo de massa no Brasil.

A Política de Desenvolvimento Produtivo (PDP), lançada em 2008, visa promover a competitividade de longo prazo da economia brasileira, garantindo o crescimento sustentável, integração dos instrumentos de política existentes, fortalecimento da coordenação entre instituições de governo e aprofundamento da articulação com o

\footnotetext{
7 Segundo dados do Ministério da Fazenda (2010), o Programa de Aceleração do Crescimento (PAC) mobilizou mais de R\$ 500 bilhões, entre 2007 e 2010, nas áreas de transporte, energia, saneamento, habitação e recursos hídricos. Em 2010, o investimento - ou formação bruta de capital fixo - cresceu 21,8\%, quase três vezes o PIB.
} 
setor privado. De forma complementar ao PAC, a PDP promoveu desonerações para o setor produtivo em virtude do aproveitamento mais rápido de créditos tributários por investimentos, depreciação acelerada e redução do imposto sobre produtos industriais (IPI) sobre bens de capital (BARBOSA, 2013, p. 78-79).

Em 2011, com o apoio de Lula, Dilma Rousseff é eleita, firmando o compromisso de dar continuidade às políticas macroeconômicas. Apesar de ter sofrido críticas quanto a estar "à sombra" de seu antecessor, Dilma logo imprimiu sua postura na condução do governo, tendo recebido altos índices de aprovação nos dois primeiros $a_{n o s}{ }^{8}$. Defensora da orientação desenvolvimentista, mesmo diante do agravamento da crise internacional ${ }^{9}$, Dilma garantiu a implementação de políticas para promover o aquecimento da economia, tais como: valorização do salário mínimo, redução das taxas de juros e do IPI, aumento do benefício do Programa Bolsa Família, retomada do PAC 2, Programa Brasil Maior e o Pronatec ${ }^{10}$.

No que tange à relação entre Estado e sociedade, tanto em contextos autoritários como democráticos, o projeto desenvolvimentista necessita de coalizões para garantir sua sustentabilidade política. Enquanto um projeto de transformação compartilhado, sua viabilidade não se limita à atuação das elites políticas, mas necessita do envolvimento dos demais atores sociais e econômicos para a formulação das políticas estratégicas (Bresser-Pereira; Theuer, 2012; Diniz, 2013). No Brasil, a frente política neodesenvolvimentista possui ampla e heterogênea composição. Identificada, principalmente, com o Partido dos Trabalhadores, no plano

\footnotetext{
${ }^{8}$ Segundo pesquisas CNI/Ibope, o percentual de entrevistados que avaliou o Governo Dilma como "ótimo" e "bom" era de 51\% em setembro de 2011 (CNI/Ibope, 2011). Já em março de 2012, este percentual sobe para 56\% (CNI/lbope, 2012).

${ }^{9}$ Diante da crise internacional de 2008, o governo adotou políticas anticíclicas, que garantiram a manutenção das taxas de crescimento mediante ampliação dos investimentos.

${ }^{10}$ A partir de 2011, o PBF é ampliado e passa a integrar o Plano Brasil Sem Miséria, tendo como foco de atuação pessoas com renda familiar per capita inferior a $\mathrm{R} \$ 70$ mensais. Segundo dados do Governo Federal, até maio de 2012, 13,5 milhões de famílias eram beneficiadas, com recursos equivalentes a 0,46\% do PIB (BRASIL, 2012). Em face dos resultados positivos de sua primeira versão, em 2011, é lançado o PAC 2, priorizando projetos estruturantes em áreas de logística, energia e núcleo social-urbano. Com tais programas, o Estado reassume o papel de indutor dos investimentos, deixando de ser mero definidor de regras para atuação do setor privado. Segundo dados do Ministério da Fazenda (2012), o montante de recursos atribuídos ao Programa subiu de R\$ 16 bilhões, em 2007, para R\$ 35,4 bilhões em 2011. Já o Programa Brasil Maior reúne ações de política industrial, tecnológica e de comércio exterior com o objetivo de mobilizar as forças produtivas e gerar crescimento sustentado. O Programa Nacional de Acesso ao Ensino Técnico e Emprego (Pronatec) tem por objetivo ampliar a oferta de cursos de educação profissional e tecnológica.
} 
social, reúne setores da burguesia, a baixa classe média, o operariado urbano e o campesinato (BoIto JR; Berringer, 2013). No plano partidário, tem como principal opositor o Partido da Social Democracia Brasileira (PSDB), o qual se opõe às políticas desenvolvimentistas em defesa de uma orientação neoliberal ortodoxa.

Para viabilizar a orientação neodesenvolvimentista, além da necessidade de uma coalizão entre partidos, o Governo Lula recorreu também à sustentação política por meio do diálogo e negociação com diferentes segmentos da sociedade civil. Frente à oposição, mais identificada com as políticas neoliberais, Lula utilizou mecanismos participativos para o debate sobre as políticas desenvolvimentistas. Nesse sentido, o projeto gestado na última década tem como característica singular um novo padrão de relações com a sociedade civil no debate sobre os principais eixos de atuação dos programas governamentais.

\section{A participação social no Governo Lula (2003-2010)}

Ao possibilitar o acesso de novos atores aos espaços institucionais, compartilhando o processo decisório juntamente com os gestores públicos, propõe-se um tipo diferente de governabilidade na administração pública federal com base na proposta participativa (FARIA, 2010). A participação política visa qualificar a gestão pública uma vez que o processo decisório passa a ser compartilhado com os cidadãos. São criados incentivos para a prestação de contas por parte dos governantes, assim como é estimulado o debate sobre temas de interesse público. Tais processos possibilitam a legitimidade das decisões coletivas e têm o potencial de qualificar as instituições democráticas.

Entre as principais iniciativas promovidas pelo Governo Federal a fim de introduzir a participação social na administração pública no período de 2003 a 2012, destacam-se: a criação da Secretaria Nacional de Articulação Social, a inclusão da participação social no processo de elaboração dos Planos Plurianuais (20042007 e 2008-2011) e a ampliação dos fóruns participativos.

Tendo em vista os compromissos de campanha e a expectativa popular quanto à abertura de canais de interlocução com a sociedade civil, foi criada, dentro da estrutura da Secretaria Geral da Presidência da República, a Secretaria Nacional de Articulação Social (SNAS). Cabe à SNAS a coordenação dos processos participativos constituídos, como conselhos e conferências, bem como a promoção do diálogo entre o governo e diferentes segmentos da sociedade civil.

Outra iniciativa pioneira foi a ampliação do diálogo social para elaboração do Plano Plurianual. Caracterizado como uma ferramenta central de planejamento das ações governamentais, o PPA 2004-2007 ampliou o escopo da participação, 
tendo acolhido contribuições de debates setoriais promovidos por Ministérios, diálogos e consultas com organizações da sociedade civil, debates promovidos pelo Conselho de Desenvolvimento Econômico e Social (CDES) e proposições dos Fóruns Estaduais de Participação Social no PPA (OLIVEIRA, 2012). Ao romper com a perspectiva de que o planejamento governamental deve ser elaborado unicamente por técnicos, o Governo Lula amplia as bases social e política do PPA ao agregar contribuições da sociedade civil sobre as ações prioritárias para o período de quatro anos. Nesse sentido, também o PPA seguinte, relativo a 20082011, contemplou a participação, tendo agregado contribuições do CDES e de outros conselhos de políticas públicas.

Quanto à ampliação dos fóruns participativos na administração federal, a pesquisa realizada pelo IPEA (2012) verificou uma variação positiva do número de programas com interfaces socioestatais no período de 2002 a 2010 ${ }^{11}$. Com base no mapeamento dos programas federais previstos nos Planos Plurianuais, o estudo também destaca que, a partir de 2002, houve um processo de diversificação de órgãos que passaram a adotar mecanismos de interlocução com a sociedade civil, com destaque para a discussão em conselhos setoriais e em conferências temáticas ${ }^{12}$.

Os conselhos e as conferências introduzem uma nova dinâmica na gestão das políticas públicas nacionais, pois agregam atores não governamentais no processo de discussão de seu conteúdo. Na medida em que a participação de representantes da sociedade civil é ampliada, emerge a possibilidade de articulação entre os participantes para a inserção de novas temáticas na agenda institucional, suscitando um processo de negociação e também de prestação de contas por parte dos gestores públicos. No caso dos conselhos, o diálogo com os representantes da sociedade civil possibilita a transparência das ações governamentais e a qualificação da gestão das políticas setoriais. Já quanto às conferências nacionais, verificam-se maiores incentivos para a articulação social e federativa, na medida em que seu funcionamento prevê etapas municipais, estaduais e regionais. Ao todo, 14 novos conselhos nacionais foram criados e 74 conferências foram convocadas durante o Governo Lula (2003-2010). Entre esses

\footnotetext{
${ }^{11} \mathrm{O}$ termo interfaces socioestatais é utilizado para designar os diversos formatos de canais de interlocução entre sociedade civil e Estado (PIRES; VAZ, 2012). A pesquisa revela que, em 2002, 81\% dos programas previstos nos PPAs possuíam algum mecanismo de interlocução com a sociedade civil. Já no ano de 2010 , esse percentual sofre uma variação positiva, passando para 92,1\%.

12 Em 2002, o percentual de ministérios e órgãos da administração federal que mantinham interfaces socioestatais era de 60,4\%. Em 2010, esse número sobe para 89,3\% (PIRES; VAZ, 2012).
} 
novos fóruns de participação, este artigo destaca a criação do Conselho de Desenvolvimento Econômico e Social (CDES).

\section{A contribuição do CDES à nova agenda desenvolvimentista}

Um exemplo emblemático da disposição em debater a temática do desenvolvimento em conjunto com representantes da sociedade civil foi a criação do Conselho de Desenvolvimento Econômico e Social em 2003. Kunrath (2005) destaca que, a fim de obter uma maior base de apoio ao programa de governo, houve o interesse em criar um conselho consultivo à Presidência, buscando também tranquilizar as forças do mercado frente à eleição de uma coligação partidária de centro-esquerda. A própria composição do CDES busca contemplar a representação das forças produtivas nacionais, com destaque para a estratégia de promover uma aproximação entre o governo e setores da elite empresarial.

O Conselho é presidido pelo Presidente da República e tem sua coordenação e funcionamento subordinados à Secretaria Executiva do Conselho, a Sedes. As principais instâncias internas do CDES são: o Pleno, os Grupos de Trabalho (GTs), o Comitê Gestor e o Observatório da Equidade (ver Figura 1). O Pleno reúne todos os conselheiros e se caracteriza como uma reunião de trabalho com periodicidade bimestral. Os GTs são criados pelo Pleno e têm como objetivo reunir conselheiros interessados em debater de forma aprofundada determinada matéria. O Comitê Gestor reúne conselheiros e integrantes da Sedes para organização e encaminhamento das atividades. Já o Observatório da Equidade é uma instância de pesquisa e monitoramento, que busca fornecer subsídios para os debates do Conselho.

O CDES é composto por representantes governamentais, na figura de ministros, e, no máximo, 90 conselheiros da sociedade civil. Seu caráter de assessoramento exclusivo ao chefe do Poder Executivo faz com que sua composição esteja subordinada à escolha presidencial, sendo que os conselheiros da sociedade civil são escolhidos de modo a combinar representatividade setorial, abrangência social e reconhecido saber. O CDES reúne conselheiros identificados como representantes de organizações da sociedade civil, sindicatos de trabalhadores, movimentos sociais, intelectuais, empresários e personalidades. Entre os participantes, numericamente, destacam-se os empresários, seguidos pelos trabalhadores. No período de 2003 a 2010, o percentual médio de participação de empresários no quadro de conselheiros não governamentais foi de $47 \%$ e o dos representantes de centrais sindicais, 21,5\% (SANTOS, 2012).

Diferentemente de outros conselhos, o CDES adota uma metodologia de funcionamento que exclui o componente do voto nas deliberações plenárias, 
Presidência da República

Secretaria de Relações Institucionais (até 2010)

Secretaria Executiva do CDES

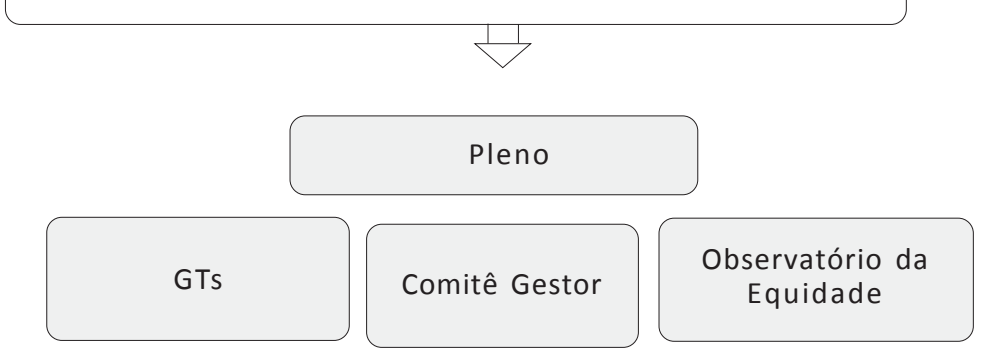

Fonte: Elaboração própria com base em BRASIL, 2003.

\section{Figura 1: Organograma do CDES}

trabalhando com a busca do consenso entre seus participantes. O produto de suas discussões não é fruto de votações, nas quais há formação de uma maioria para deliberação quanto às propostas. O Conselho utiliza a prática da concertação social, a fim de promover um esforço dialógico de negociação e convencimento para elaboração de proposições em bases consensuais ${ }^{13}$. Até 2010, o CDES se inseriu no processo de elaboração dos Planos Plurianuais de governo, tendo produzido também três documentos estratégicos para o debate sobre o modelo de desenvolvimento almejado. As principais produções do CDES foram a Agenda Nacional de Desenvolvimento (AND/2005), os Enunciados Estratégicos para o Desenvolvimento (EED/2006) e a Agenda para um Novo Ciclo de Desenvolvimento (ANC/2010).

A AND resultou de um longo processo de diálogo e de diagnóstico inicial, que envolveu a realização de 26 reuniões durante os anos de 2004 e 2005. A Agenda propõe estratégias e enfoques prioritários para a garantia da equidade, a dinamização da economia interna e externa e o aperfeiçoamento do aparato

\footnotetext{
${ }^{13}$ A concertação social proposta pelo CDES pode ser compreendida pelo seguinte trecho da Primeira Carta de Concertação: "Como resultado do processo histórico e político, não temos uma cultura do diálogo, de interlocução real e positiva com todos os setores. Referenciados na tolerância e na diversidade, na disposição de ouvir as ideias contrárias, o CDES busca a construção do consenso. Através da explicitação das divergências, das múltiplas e legítimas visões que nos constituem, é possível construir as convergências (CDES, 2003, p. 2)".
} 
estatal frente a um novo contexto político de retomada das capacidades de investimento público em políticas sociais. Além disso, tem por objetivo ser um documento estratégico com diretrizes para a superação dos entraves ao desenvolvimento nacional. Tendo em vista uma perspectiva de planejamento de longo prazo, são propostas diretrizes para ações de enfrentamento em quatro eixos: políticas sociais, políticas econômicas, políticas de infraestrutura logística e políticas de aperfeiçoamento do aparato estatal (CDES, 2005). Tais diretrizes teriam como meta construir:

Um país democrático e coeso, no qual a iniquidade foi superada, todas as brasileiras e todos os brasileiros têm plena capacidade de exercer sua cidadania, a paz social e a segurança pública foram alcançadas, o desenvolvimento sustentado e sustentável encontrou o seu curso, a diversidade, em particular a cultural, é valorizada. Uma nação respeitada e que se insere soberanamente no cenário internacional, comprometida com a paz mundial e a união entre os povos (CDES, 2005, p. 13).

Ao comparar a AND à Carta ao Povo Brasileiro, nota-se grande similaridade entre seus conteúdos. A Carta, escrita durante a campanha, sintetiza o programa do Governo Lula. Já a AND revela o esforço dialógico entre o governo eleito e a sociedade civil no intuito de definir diretrizes para a atuação do Estado numa perspectiva desenvolvimentista de médio e longo prazos. Apesar de terem datas diferentes, ambos os documentos são produtos do mesmo processo de transição e de inflexão da política econômica nacional. A partir da leitura, é possível afirmar que os dois documentos convergem quanto aos seguintes pontos: ampliação do mercado interno, fortalecimento das capacidades estatais, viabilização das reformas agrária e tributária, redução das desigualdades sociais e promoção de justiça e segurança pública (SILVA, 2002; CDES, 2005).

Tendo em vista que a alteração no conteúdo das políticas envolve um campo de disputas e de correlação de forças, a AND foi o primeiro passo rumo à pactuação social sobre as políticas desenvolvimentistas, envolvendo setores estratégicos como o empresariado e os trabalhadores. A elaboração da AND deu visibilidade ao tema e o inseriu de forma definitiva na agenda política do governo em 2006. Nesse sentido, a base social de apoio do Conselho e a troca da equipe do Ministério da Fazenda possibilitaram que a orientação desenvolvimentista se acentuasse.

Também em 2006, são elaborados os Enunciados Estratégicos para o Desenvolvimento, dando continuidade ao debate suscitado pela AND. Produto de cinco reuniões regionais e três reuniões plenárias, o documento contempla 24 diretrizes para a promoção do desenvolvimento em uma perspectiva de longo prazo. São estabelecidas metas a serem atingidas até o ano de 2022, contemplando 
temas como política econômica, educação, saúde, valorização do salário mínimo, redução das taxas de juro, reforma fiscal, política industrial, infraestrutura, ciência e tecnologia, entre outros (CDES, 2006). Seu conteúdo contempla o que foi proposto inicialmente pela AND, no entanto, apresenta diretrizes operacionais quanto às temáticas. Também um diferencial foi o debate ampliado nas cinco regiões do País: Sudeste, Sul, Centro-Oeste, Norte e Nordeste.

Após cinco anos do encaminhamento das proposições da AND e diante dos efeitos da crise econômica e financeira internacional de 2008, em 2010, o comitê gestor do Pleno do CDES sugeriu a redação de um novo documento orientador, inserindo-se em um momento avaliativo dos resultados alcançados pela Agenda anterior. Em julho de 2010, foi aprovada, pela 34ạ Reunião do Pleno, a Agenda Nacional para um Novo Ciclo de Desenvolvimento (ANC). Tendo em vista que o conteúdo dos Enunciados para o Desenvolvimento retoma os principais eixos da AND, a seguir é apresentada a figura com os eixos prioritários da AND e da ANC.

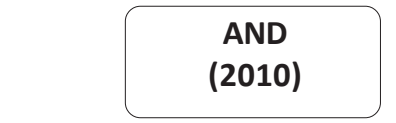

Eixos prioritários para enfrentamento:

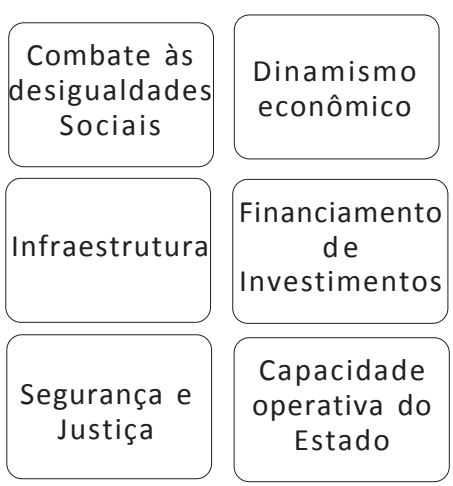
(2010)

Eixos prioritários para enfrentamento:
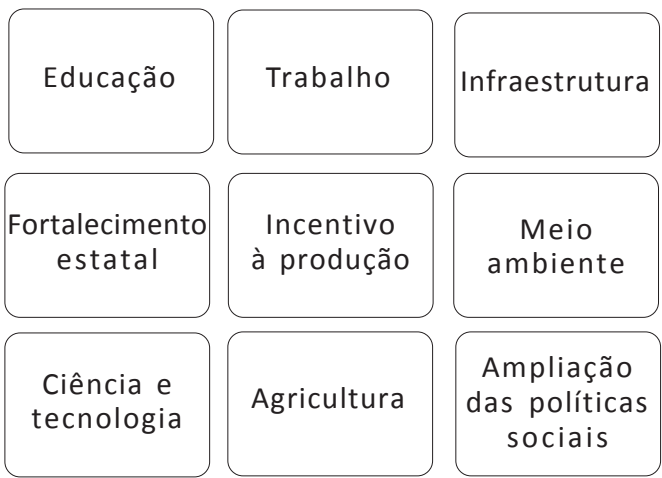

Fontes: Elaboração própria com base em CDES, 2005; CDES, 2010a.

Figura 2: Síntese da AND e da ANC

Se a AND fornece o diagnóstico inicial para a retomada do projeto desenvolvimentista, a ANC propõe diretrizes para um novo momento econômico, no qual são considerados urgentes os investimentos estatais em políticas de infraestrutura e de proteção social. Nesse sentido, sugere a adoção de políticas econômicas anticíclicas e garantidoras da capacidade de investimentos públicos, a fim de diminuir os impactos da conjuntura internacional na economia brasileira por meio da garantia do mercado interno, da renda, do emprego e da expansão do 
acesso ao crédito (CDES, 2010a). Nesse sentido, a ANC tem um conteúdo mais detalhado quanto às ações a serem empreendidas pelo governo. Embora mantenha os mesmos valores e a mesma visão de futuro que haviam sido propostos pela Agenda anterior, a Agenda para um Novo Ciclo de Desenvolvimento propõe dois eixos principais para a garantia do desenvolvimento: 1) a consolidação do processo de expansão equânime do emprego e da renda, com fortalecimento do mercado interno; e 2) a inserção na economia internacional. Os desafios a serem enfrentados para alcançá-los seriam: educação, fortalecimento do Estado democrático e indutor do desenvolvimento, estímulo à ciência e tecnologia, trabalho e inclusão produtiva, incentivo à produção, agricultura, infraestruturas (transporte, energia, comunicação, água e saneamento), sustentabilidade ambiental e consolidação e ampliação das políticas sociais (CDES, 2010a, p.3).

$O$ conteúdo referente às políticas sociais, que estava minimizado na primeira Agenda do CDES, ganha destaque no texto da ANC. A defesa da consolidação e ampliação das políticas sociais possibilitou maior legitimidade à atuação do governo, principalmente num contexto de crise internacional, no qual há estímulos para a redução dos investimentos em áreas sociais. A ANC propõe o fortalecimento da institucionalidade das políticas sociais, garantindo-Ihes o caráter de políticas de Estado. Ainda sobre a inclusão social e o acesso à renda e aos serviços públicos, o documento orienta:

Contemplar a redistribuição da renda e da riqueza, a promoção da equidade e a garantia de políticas universais baseadas em direitos integrais que afetam o conjunto das dimensões que definem a qualidade de vida. Garantir seguridade econômica por meio de transferências condicionadas e/ou renda universal básica capaz de prover os núcleos familiares e os indivíduos de um mínimo de ativos. (CDES, 2010a, p. 27).

A fim de consolidar um novo padrão de relações entre o governo e a sociedade civil sobre a temática do desenvolvimento, há consenso entre os conselheiros do CDES sobre a necessidade de fortalecer mecanismos de participação e controle social nos poderes Executivo, Legislativo e Judiciário. No item que versa sobre o aprofundamento democrático, a ANC orienta o Estado a garantir a informação e a transparência com o objetivo de consolidar “(...) mecanismos que ampliem a participação da sociedade no processo decisório, no planejamento e na avaliação das ações governamentais, nas definições e acompanhamento do orçamento" (CDES, 2010a, p. 13).

A AND revela um esforço inicial para diagnóstico e reflexão dos entraves para o desenvolvimento, que se realizou nos dois primeiros anos do conselho. Já a ANC, lançada em 2010, é produto de sete anos de trabalho e debates internos, 
que Ihe conferem, qualitativamente, maiores subsídios. Nas palavras do Secretário-Executivo do CDES:

Acho que o esforço da Agenda [ANC] reconhece também que o Brasil construiu um novo modelo de desenvolvimento econômico e social e que esse Conselho foi parte integrante da construção desse novo modelo. E por último, o esforço da agenda reconhece esse espaço como espaço legítimo de diálogos da sociedade. Foi no momento da crise que isso se legitimou entre todos nós, quando o governo utilizou e sentou com o Conselho para discutir as saídas da crise. E nesse momento o Conselho é chamado para apresentar qual é a agenda que ele vê para esse período pós-crise. Nesse sentido, ele tem um papel fundamental que é ocupar o espaço que está aberto para outras instituições, outros atores ocuparem, e nós queremos estimular o Conselho de Desenvolvimento Econômico e Social a ocupar, de forma definitiva, esse espaço (CDES, 2010b, p.4).

Este artigo buscou analisar como o estilo de planejamento estatal mais participativo exerce influência sobre o modelo de desenvolvimento. A criação de um colegiado com participação majoritária da sociedade civil revela a busca por parte do governo em construir novos espaços de interlocução sobre a temática do desenvolvimento, de modo a elaborar políticas mais inclusivas e promotoras de mudanças sociais.

Além de possibilitar a troca de informações entre os representantes governamentais e os participantes da sociedade civil, espaços como o CDES têm o potencial de criar uma base de sustentação política do governo, sobretudo quanto a temáticas de difícil tramitação no Legislativo. Dentre seus objetivos, o CDES visava promover uma concertação no âmbito das relações políticas para dar sustentação também a um conjunto de reformas institucionais, caracterizadas como a "segunda geração" de reformas do Consenso de Washington, que são a reforma da previdência, da legislação trabalhista e tributária (CDES, 2006). No entanto, é preciso destacar que o conteúdo referente às reformas institucionais foi parcialmente acordado no período de 2003 a 2010. Até 2005, o governo aprovou duas importantes reformas: a minirreforma tributária e a reforma da previdência. Porém, houve dificuldades para o encaminhamento das reformas agrária, trabalhista e política. Mesmo com o apoio do Conselho, o governo não avançou no sentido de promover mudanças significativas nas temáticas referidas.

Ainda que não tenha ocorrido uma participação formal do CDES no processo decisório que deu origem ao PAC, Tapia (2007) afirma que há certa assimilação das contribuições da Agenda Nacional do Desenvolvimento quanto às temáticas de logística, transporte, habitação, desenvolvimento urbano e saneamento. Nesse 
sentido, o autor afirma que, no plano simbólico, a menção à contribuição do CDES às diretrizes formuladoras do PAC contribui para garantir legitimidade ao Conselho num contexto de crise política do governo.

Em 2011, o CDES empreendeu um esforço de monitoramento das recomendações dos Enunciados Estratégicos para o Desenvolvimento (EED). No documento, há análises de dados do desempenho governamental nas seguintes áreas: reformas estruturais, macroeconomia, política tributária, sistema financeiro, desigualdade social, entre outras. Quanto ao conteúdo da política tributária, os EED recomendavam reduzir a carga fiscal como proporção do Produto Interno Bruto (PIB) para um patamar em torno de $33 \%$ no prazo máximo de cinco anos, contado a partir de 2006. Porém, os dados sobre o percentual da carga tributária no período de 2006 a 2010 revelam tendência no sentido oposto, tendo oscilado de 34,12\%, em 2006, a 35\%, em 2010 (CDES, 2011).

Quanto às recomendações de expansão do crédito, houve avanços significativos. Segundo dados do Ministério da Fazenda, compilados pelo CDES, o crédito total concedido pelo sistema financeiro passou de $28,48 \%$, em 2006 , para 41,25\%, em 2009 (CDES, 2011, p. 26). Também quanto às recomendações sobre expansão do comércio exterior, os dados sobre a exportação demonstram relativo aumento com taxas superiores a 15\%, em 2006 e 2007, e 23,21\%, em 2008. Essa tendência é rompida em 2009 em decorrência da crise econômica mundial.

No que tange às recomendações gerais presentes nos EED, AND e ANC quanto à redução das desigualdades e redistribuição de renda, há discretos avanços que podem ser medidos pelo Índice de $\mathrm{Gini}^{14}$ e pelo índice de Desenvolvimento Humano ${ }^{15}$ (IDH). Segundo dados do IPEA (2010b), em 2003, o coeficiente de Gini era de 0,580 e sofreu redução para 0,538 em 2009. Em 2010, foi reformulada a metodologia de cálculo do IDH. Para possibilitar a comparabilidade, foram recalculados os dados para os anos anteriores. Segundo informe do Programa das Nações Unidas para o Desenvolvimento (PNUD), de 2000 a 2010, o IDH brasileiro

\footnotetext{
${ }^{14} \mathrm{O}$ Índice de Gini mede o grau de desigualdade na distribuição da renda domiciliar per capita entre os indivíduos. Seu valor pode variar de zero, quando não há desigualdade, até 1, quando a desigualdade é máxima.

${ }^{15} \mathrm{O}$ IDH varia entre zero e 1 (quanto mais próximo de 1 , maior o nível de desenvolvimento humano). Apesar das críticas sobre sua utilização e da dificuldade quanto à comparação de realidades sociais distintas, o IDH oferece uma mensuração sobre o desenvolvimento humano, com base nas condições de saúde, educação e renda. É calculado anualmente pela Organização das Nações Unidas desde 1990. A partir de 2010, foram introduzidas mudanças nos indicadores para o cálculo do índice.
} 
teve um ganho de 7,6\% (PNUD, 2010). Referente ao ano de 2010, o índice de 0,699 situa o Brasil entre os países de alto desenvolvimento humano.

Enquanto um colegiado com caráter consultivo, seu funcionamento visa atender às demandas da Presidência, buscando construir deliberações consensuais sobre temáticas de interesse estratégico para o desenvolvimento. Para tanto, busca promover a interlocução dos representantes da sociedade civil com a equipe ministerial. Sem o poder de constituir decisões vinculantes aos conteúdos das políticas, tendo em vista seu caráter consultivo, o CDES revela um esforço inicial por parte da Presidência na promoção de um local de escuta aos diferentes atores sociais. Porém, mesmo após uma década de funcionamento e relativa institucionalização, há necessidade de estudos futuros que aprofundem a análise sobre a qualidade das deliberações e a efetividade do CDES em termos de aproveitamento de suas sugestões às políticas governamentais num momento de construção de uma nova agenda desenvolvimentista.

O CDES tanto fornece orientações gerais para a elaboração das políticas desenvolvimentistas, por meio das Agendas e dos Enunciados Estratégicos, quanto possibilita a interlocução sobre o conteúdo das políticas governamentais na ocasião de seus lançamentos. As principais ações do governo são apresentadas nas reuniões plenárias, sendo que os conselheiros questionam os ministros responsáveis no caso de dúvidas ou sugestões sobre seus conteúdos. No entanto, a análise da atuação do CDES revela lacunas quanto à fase posterior ao lançamento dessas políticas. As orientações, dúvidas e sugestões são encaminhadas à equipe governamental, mas são limitados os esforços no sentido de acompanhar e monitorar o processo de implementação e execução. Nesse sentido, a participação de representantes do CDES nos núcleos de gestão das políticas teria o potencial de qualificar o processo de concertação e promover maior sinergia entre os participantes da sociedade civil e os gestores públicos para o sucesso das novas políticas desenvolvimentistas.

\section{Considerações finais}

Em um contexto democrático e de relativa estabilização econômica, o Governo Lula buscou retomar o debate sobre o desenvolvimento nacional. Desde o momento da campanha presidencial, em 2002, verificou-se o interesse em construir as bases de um novo Estado desenvolvimentista em diálogo com a sociedade. Diferentemente do velho nacional-desenvolvimentismo experimentado em décadas anteriores, o modelo proposto passou a ser compreendido pela dupla adjetivação: desenvolvimento econômico e social. Isto é, para além do crescimento 
econômico, desenvolver implicaria a redução das desigualdades sociais mediante a intervenção estatal. Para tanto, o Governo Federal firmou compromissos quanto à redução da pobreza extrema e quanto à melhoria das condições básicas de vida da população. O gasto social passou a ser concebido tanto como um estímulo ao crescimento econômico quanto um instrumento minimizador das desigualdades.

A inflexão proposta pelo Governo Lula, em especial a partir de 2006, se fundamenta na ruptura com a orientação que concebe que a superação da condição de subdesenvolvimento ocorreria de forma espontânea e natural pela livre atuação das forças de mercado. Rompe-se, portanto, com a ideia de que os avanços sociais são subprodutos da estabilização monetária. Atualmente, a dinamização da economia brasileira tem como principais vetores o ativismo estatal e os gastos sociais. Mesmo com o advento da crise internacional de 2008, evidenciou-se a capacidade do governo em promover políticas anticíclicas, que garantiram o fortalecimento da economia nacional mediante a ampliação dos investimentos nas políticas sociais e nos setores estratégicos de infraestrutura. Assim, o ciclo de dinamismo econômico e social, iniciado no Governo Lula teve continuidade com a eleição da Presidenta Dilma Roussef, em 2011.

Com base nos dados apresentados, é possível perceber que a retomada de políticas promotoras do desenvolvimento nacional teve como singular característica a ampliação e diversificação dos canais de interlocução com a sociedade civil. Entre os novos fóruns de participação, neste artigo, buscou-se apresentar a contribuição do CDES à agenda desenvolvimentista. A experiência do CDES fornece subsídios para a reflexão sobre as dificuldades e potencialidades da articulação entre Estado desenvolvimentista e aprofundamento democrático. Verificou-se que a atuação do Conselho teve como objetivo a construção de uma agenda mínima, consensuada entre os conselheiros da sociedade civil sobre o tema. Diante da oposição, identificada com políticas de orientação neoliberal, o governo brasileiro teve um importante fórum enquanto aliado e defensor de seu programa.

Na medida em que a retomada de um Estado desenvolvimentista implica uma correlação de forças para a viabilização das políticas, o CDES forneceu condições propícias para o diálogo social para além das disputas político-partidárias, envolvendo também trabalhadores, empresários e representantes da sociedade civil organizada. Tendo em vista que o conteúdo das políticas é debatido com os representantes da sociedade civil, cresce a possibilidade de construção de um modelo de desenvolvimento inclusivo e atento às demandas por justiça social e equidade. Além disso, a participação em instâncias de planejamento estatal tem o potencial de promover um ambiente democrático e cooperativo, no qual há estímulos para troca de informações e transparência das ações públicas. 
No entanto, a atuação do Conselho ainda revela lacunas no que tange à sua composição e ao monitoramento das políticas desenvolvimentistas. Tendo em vista que o empresariado possui elevado número de assentos, a qualificação desse espaço de participação social implica a revisão da forma de indicação e a ampliação do número de representantes das organizações da sociedade civil. Somente assim será possível potencializar a capacidade inclusiva e de diálogo com amplos setores sociais acerca da temática do desenvolvimento.

Quanto ao monitoramento das políticas, acredita-se que a incidência do Conselho pode contribuir para qualificar o processo de implementação. Nesse sentido, é fundamental que a participação social não se restrinja a influenciar a elaboração da agenda e/ou ratificar as ações governamentais. Há necessidade de acionar mecanismos de diálogo em todas as etapas do ciclo de políticas públicas, a fim de garantir maior transparência, prestação de contas e qualificação da gestão pública. Para que o novo projeto desenvolvimentista seja inclusivo e instrumento de justiça social, é fundamental a participação dos mais variados segmentos sociais nos processos de debate, consulta, monitoramento e avaliação dos programas que o constituem.

\section{Referências bibliográficas}

Avritzer, L.; Santos, B. de Souza. Para ampliar o cânone democrático. In: SAntos, Boaventura de Souza (org). Democratizar a democracia: os caminhos da democracia participativa. Rio de Janeiro: Editora Civilização Brasileira, 2002.

BARBosa, N.; SouzA, J. A. P. A inflexão do Governo Lula: política econômica, crescimento e distribuição de renda. In: SADER, E.; GARCIA, M. A. (Orgs.) Brasil: entre o passado e o futuro. São Paulo: Fundação Perseu Abramo, 2010.

. Dez anos de política econômica. In: SADER, E. (Org.) 10 anos de governos

pós-neoliberais no Brasil: Lula e Dilma. São Paulo, SP: Boitempo; Rio de Janeiro: FLACSO Brasil, 2013.

Boito JR, A.; Berringer, T. Brasil: Classes sociais, neodesenvolvimentismo e política externa nos governos Lula e Dilma. Rev. Sociol. Polít., Curitiba, v. 21, n. 47, p. 31-38, set. 2013.

BRASIL. Decreto-Lei n. 4.744, de 16 de junho de 2003. Dispõe sobre a composição e o funcionamento do Conselho de Desenvolvimento Econômico e Social. Diário Oficial da União, Brasília, 17 jun. 2003.

Brasil. Ministério da FAzenda. Economia brasileira em perspectiva: Edição especial. Brasília: 2010. Disponível em: <http://www.fazenda.gov.br/divulgacao/ publicacoes/economia-brasileira-em-perspectiva/economia_brasileira_ em_perspectiva_pt_ed_especial_2010.pdf > Acesso em: 02 mai 2014. 
Economia brasileira em perspectiva: 15a Edição. Brasília: 2012. Disponível em: <http://www.fazenda.gov.br/portugues/docs/perspectivaeconomia-brasileira/edicoes/Economia-Brasileira-Em-Perpectiva-Mar-Abr12alterado.pdf> Acesso em: 09 mai 2013.

Bresser-Pereira, L. C. O novo desenvolvimentismo e a ortodoxia convencional. São Paulo em Perspectiva, v. 20, n. 3, p. 5-24, 2006.

Bresser-Pereira, L. C; Theuer, D. Um Estado novo-desenvolvimentista na América Latina? Economia e sociedade, Campinas, v. 21, número especial, p. 811-829, 2012. Cepêda, V. A. Inclusão, democracia e novo-desenvolvimentismo. Revista Estudos Avançados, São Paulo, v. 26, n. 75, p. 77-90, 2012.

CNI/IBOPE. Avaliação do governo (setembro 2011). Brasília: CNI, 2011. Disponível em: <http://www.cni.org.br/portal/lumis/portal/file/fileDownload.jsp?fileld= FF80808132A7941C0132BAF5E83D50BF>. Acesso em 06 dez. 2013.

Avaliação do governo (março 2012). Brasília: CNI, 2012. Disponível em: <http://www.ibope.com.br/ptbr/conhecimento/relatoriospesquisas/Lists/ RelatoriosPesquisaEleitoral/OPP\%20112253-3\%20-\%20CNI\%20-\%20Avalia\% C3\%A7\%C3\%A30\%20do\%20governo\%20federal\%20publica\%C3\%A7\%C3\% A3o.pdf>. Acesso em 06 dez. 2013.

Conselho de Desenvolvimento Econômico e Social (CDes). Primeira Carta de Concertação: Ação política para a mudança e a concertação [2003]. Disponível em: <http:// www.cdes.gov.br/conteudo/15069/documentos-de-orientacao-estrategica.html >. Acesso em: 20 fev. 2012.

Agenda Nacional de Desenvolvimento [2005]. Disponível em: <http:// www.cdes.gov.br> Acesso em: 18 fev. 2012.

Enunciados Estratégicos para o Desenvolvimento [2006]. Disponível em: <http://www.cdes.gov.br/conteudo/15069/documentos-de-orientacaoestrategica.html > Acesso em: 29 nov. 2013.

Agenda Nacional para um Novo Ciclo de Desenvolvimento [2010a]. Disponível em: <http://www.cdes.gov.br> Acesso em: 18 fev. 2012.

Ata da 34 Reunião do Pleno [2010b]. Disponível em: <http:// www.cdes.gov.br/evento/5442/pleno-do-cdes-reuniao-ordinaria- $\mathrm{n}^{\circ} 34 . \mathrm{html}^{\mathrm{s}} \textrm{ }$ Acesso em: 18 fev 2012.

. Monitoramento dos Enunciados Estratégicos para o Desenvolvimento. [2011] Disponível em: <http://www.cdes.gov.br/materias_aprovadas.html?tipo=5>. Acesso em: 05 dez. 2013.

DıNız, E. Desenvolvimento e Estado desenvolvimentista: tensões e desafios da construção de um novo modelo para o Brasil do século XXI. Rev. Sociol. Polít., Curitiba, v. 21, n. 47, p. 09-20, 2013. 
. Empresários e governo Lula: percepções e ação política entre 2002 e 2006. Anais do Workshop Empresa, Empresários e Sociedade, realizado em Porto Alegre, 2006. Disponível em: <http://www.fee.rs.gov.br/5workshop/pdf/ mesa02_eli.pdf> Acesso em: 28 abr 2014.

ERBER, F. S. As convenções de desenvolvimento no governo Lula: um ensaio de economia política. Revista de Economia Política, São Paulo, vol. 31, no 1 (121), p. 31-55, 2011.

Evans, P. Constructing the 21st Century Developmental State: potentialities and pitfalls. In: EDIGHEJ, O. (ed.). Constructing a Democratic Developmental State in South Africa: potentials and challenges. Cape Town: HSRC, 2010.

FARIA, C. F. Estado e organizações da sociedade civil no Brasil contemporâneo: Construindo uma sinergia positiva? Rev. Sociol. Política, Curitiba, v. 18, n. 36, p. 187-204, 2010.

Furtado, C. Criatividade e desenvolvimento em época de crise. Rio de Janeiro: Paz e Terra, 1984.

Gonçalves, R. Novo desenvolvimentismo e liberalismo enraizado. Serv. Soc. Soc., São Paulo, n. 112, p. 637-671, 2012.

HerRlein JR., R. A construção de um Estado democrático para o desenvolvimento no século XXI. In: Texto para discussão/ Instituto de Pesquisa Econômica Aplicada. Rio de Janeiro: IPEA, 2014.

instituto de Pesquisa Econômica Aplicada. Perspectivas do desenvolvimento brasileiro. Brasília: IPEA, 2010a.

. Comunicados do IPEA - PNAD 2009: Primeiras análises (no 63).

Brasília: IPEA, 2010b.

. Gasto social federal: uma análise da execução orçamentária de 2011.

Nota técnica nํ 13. Brasília: IPEA, 2012.

KunRath, R. J. CDES: O Conselho de Desenvolvimento Econômico e Social do Brasil. Dissertação de Mestrado - Programa de Pós Graduação em Ciência Política. Universidade Federal do Rio Grande do Sul, UFRGS, Porto Alegre, 2005.

Morais, L; SAAD-FILHo, A. Da economia política à política econômica: o novodesenvolvimentismo e o governo Lula. Revista de Economia Política, São Paulo, vol. 31, no 4, p. 507-527, 2011.

Lula and the continuity of neoliberalism in Brazil: strategic choice, economic imperative or political schizophrenia? Historical Materialism, 13, p. 331, 2005.

Nogueira, M. A. Um Estado para a sociedade civil: temas éticos e políticos para a gestão democrática. São Paulo: Cortez, 2004.

Oliveira, V. R. O processo de participação social nos Planos Plurianuais do Governo Federal. In: Silva, E. M.; Soares, L. B. (Orgs.) Experiência de Participação Institucionalizada. Belo Horizonte: UFMG/FAFICH, 2013. 
PAULANI, L. Brasil delivery: razões, contradições e limites da política econômica nos primeiros seis meses do Governo Lula. In: PAULA, J. A. de (org.) A economia política da mudança. Belo Horizonte: Autêntica, 2003.

PNUD. Brasil sobe quatro posições no novo IDH; avanço é o mais expressivo de 2009 a 2010. Disponível em: < http://www.pnud.org.br/Noticia.aspx?id=2394> Acesso em: 15 dez 2010.

Pires, R. R. C.; Gomide, A. A. Burocracia, democracia e políticas públicas: arranjos institucionais de políticas de desenvolvimento. In: Texto para discussão/Instituto de Pesquisa Econômica Aplicada. Rio de Janeiro: IPEA, 2014.

; VAz, A. Participação social como método de governo: um mapeamento das "interfaces socioestatais" nos programas federais. Rio de Janeiro: IPEA, 2012. SAntos, P. R. A institucionalização da participação no Governo Lula: um estudo de caso sobre o CDES. Dissertação de Mestrado - Programa de Pós Graduação em Ciência Política. Universidade Federal do Rio Grande do Sul, UFRGS, Porto Alegre, 2012.

Sıcsú, J. et al. (Org.) Novo-desenvolvimentismo: um projeto nacional de crescimento com equidade social. Rio de Janeiro: Fundação Konrad Adenauer, 2005.

Silva, L. I. L. Carta ao Povo Brasileiro (de 22 de junho de 2002). Documento informativo do Partido dos Trabalhadores. Disponível em: <http:// www.fpa.org.br> Acesso em: 18 fev. 2013.

SINGER, P. Os sentidos do lulismo: reforma gradual e pacto conservador. São Paulo: Companhia das Letras, 2012.

TAPIA, J. R. B. Conselho de desenvolvimento econômico e social: os desafios da construção institucional. In: DINız, Eli (Org.). Globalização, Estado e desenvolvimento: dilemas do Brasil no novo milênio. Rio de Janeiro: Editora FGV, p. 180-233, 2007. VAZ, A. PIRES, R. Participação social como método de governo? Uma agenda de pesquisa sobre as interfaces socioestatais no governo federal. In: IPEA. Boletim de Análise Político-Institucional n. 1. Brasília: IPEA, 2011.

Priscilla Ribeiro dos Santos

Mestra (2012) e doutoranda em Ciência Política pela Universidade Federal do Rio Grande do Sul (UFRGS). Contato: pciasantos@gmail.com 